\title{
Profil penggunaan obat antidiabetes pada pasien diabetes mellitus tipe 2 di instalasi rawat jalan RSUD Provinsi NTB tahun 2018
}

Baiq Sofianti Annisa ${ }^{*}$, Candra Eka Puspitasari ${ }^{1}$, Siti Rahmatul Aini ${ }^{1}$

1Program Studi Farmasi, Fakultas Kedokteran, Universitas Mataram, Mataram, Indonesia.

DOI: https://doi.org/10.29303/sjp.v2i1.74

Article Info

Received : 2020-12-21

Revised : 2021-04-29

Accepted: 2020-04-29

\begin{abstract}
Abstrak: Diabetes mellitus (DM) is a disorder of insulin secretion, insulin action or both, which are characterized by blood glucose levels $>200 \mathrm{mg} / \mathrm{dl}$ and / or fasting blood glucose levels $>126 \mathrm{mg} / \mathrm{dl}$. In 2017 Indonesia was recorded as the sixth largest country with DM in the world. The most common classification of diabetes is type 2 DM with an incidence 90$95 \%$. The study aimed to determine the profile of antidiabetic use in type $2 \mathrm{DM}$ patients at the outpatient department of RSUD Provinsi NTB in 2018. This study used cross sectional design retrospectively with purposive sampling method for the period January-December 2018. The results showed that in 112 patients, 195 antidiabetic agents were prescribed. The antidiabetic prescribed were metformin (33.85\%), glimepirid $(25.13 \%)$, aspart insulin $(13.33 \%)$, insulin detemir $(8.21 \%)$, pioglitazone $(6.67 \%)$, insulin glargine $(6.67 \%)$, glyclazide $(1.54 \%)$, gliquidone $(1.54 \%)$, acarbose $(1.54)$, regular insulin $(1.03 \%)$, and insulin lispro $(0.51 \%)$. Overall, antidiabetic use was in accordance with the guideline recommendations. Further research is needed regarding the review of prescriptions and detailed indications in order to increase rationality of drug use, reduce morbidity and mortality and reduce medical costs.
\end{abstract}

Keywords: Type 2 DM, blood glucose, outpatient, antidiabetic, metformin

Citation: Annisa, BS., Puspitasari, CE., \& Aini, SR. (2021). Profil penggunaan obat antidiabetes pada pasien diabetes mellitus tipe 2 di instalasi rawat jalan RSUD Provinsi NTB tahun 2018. Sasambo Journal of Farmasi, 2(1), 37-41. doi: https://doi.org/10.29303/sjp.v2i1.74

\section{Pendahuluan}

Diabetes mellitus (DM) merupakan penyakit kelainan sekresi insulin, kerja insulin atau keduanya yang ditandai dengan kadar glukosa darah sewaktu $>200 \mathrm{mg} / \mathrm{dl}$ dan atau kadar glukosa darah puasa >126 $\mathrm{mg} / \mathrm{dl}$ (PB PERKENI, 2015). Prevalensi DM (usia 18-99 tahun) di dunia menurut International Diabetes Federation (IDF) tahun 2017 mencapai 8,4\% atau 451 juta orang dan diprediksi naik menjadi $9,9 \%$ atau 639 juta orang pada tahun 2045 (Cho et al., 2018). Indonesia menempati urutan keenam penderita DM terbanyak (10,3 juta orang) setelah Cina, India, Amerika, Brazil dan Mexico (International Diabetes Federation, 2017). Berdasarkan data Dinas Kesehatan Nusa Tenggara Barat (Dinkes NTB), DM termasuk ke dalam 10 penyakit terbanyak yang diderita dengan jumlah kasus sebesar 25.084 kasus (Dinas Kesehatan NTB, 2017).
Klasifikasi DM terbagi menjadi DM tipe 1, DM tipe 2, dan Diabetes Gestasional (International Diabetes Federation, 2013). Klasifikasi diabetes yang paling sering terjadi di dunia adalah DM tipe 2 dengan proporsi kejadian 90-95\% (American Diabetes Association, 2018). Faktor yang mempengaruhi terjadinya DM tipe 2 antara lain usia, jenis kelamin, genetik, dan pola hidup (Murad et al., 2014). DM tipe 2 yang tidak terkontrol dapat menimbulkan komplikasi yang dapat memperburuk kualitas hidup bahkan menyebabkan kematian (Edwina \& Manaf, 2015).

Terapi dengan obat antidiabetes pada prinsipnya adalah untuk mengendalikan kadar glukosa darah hingga mendekati batas normal (Almasdy, Sari, Suhatri, Darwin, dan Kurniasih, 2015). Batas normal bagi pasien DM tipe 2 yang telah menerima terapi antidiabetes adalah dibawah nilai HBA1c 7\% (PB

Email: baiqsofiantia@gmail.com $\left({ }^{*}\right.$ Corresponding Author) 
PERKENI, 2015). Terapi dengan obat antidiabetes terbukti mampu mengurangi resiko atherosclerosis cardiovascular disease (ASCVD) dan komplikasi diabetes yang dapat memperparah kejadian diabetes (American Diabetes Association, 2019b). Berdasarkan hal tersebut, maka dilakukanlah penelitian dengan tujuan untuk mengetahui profil penggunaan obat antidiabetes pada pasien DM Tipe 2 di instalasi rawat jalan RSUD Provinsi NTB tahun 2018.

\section{Metode}

Penelitian ini merupakan penelitian cross sectional secara retrospektif dengan menelaah data rekam medis pasien. Sampel yang digunakan adalah rekam medis pasien DM tipe 2 instalasi rawat jalan yang memenuhi kriteria inklusi berupa data rekam medis pasien, dengan dan tanpa penyakit penyerta yang berusia $\geq 18$ tahun, serta data rekam medis pasien yang memiliki data lengkap dan terbaca. Sampel akan dieksklusi untuk pasien hamil serta pasien DM tipe 2 dengan penyakit penyerta kanker dan HIV/AIDS.

Variabel dalam penelitian ini meliputi data karakteristik pasien (usia, jenis kelamin, dan penyakit penyerta), dan jenis obat antidiabetes. Analisis data dilakukan secara deskriptif. Data penelitian yang diperoleh diedit dan ditabulasikan dalam bentuk tabel menggunakan Microsoft Office Excel ${ }^{\mathrm{TM}}$, kemudian dilakukan pengolahan data agar didapat persentase.

\section{Hasil dan Pembahasan}

Dari 113 pasien DM tipe 2 instalasi rawat jalan RSUD Provinsi NTB tahun 2018, terdapat 112 pasien yang memenuhi kriteria inklusi dan eksklusi. Pasien yang terkesklusi disebabkan pasien memiliki penyakit penyerta kanker. Hal ini disebabkan pasien dengan penyakit penyerta kanker memiliki alur terapi yang berbeda klarena keduanya merupakan penyakit yang kompleks dan membutuhkan analisa nutrisi yang detail (Psarakis, 2006). Profil karakteristik pasien yang memenuhi kriteria inklusi dapat dilihat dalam Tabel 1.

Pada penelitian ini DM tipe 2 lebih banyak terjadi pada perempuan dibanding laki-laki. Hal ini karena terdapat pengaruh hormonal, terutama pada perempuan dengan kadar estrogen rendah (biasanya pada perempuan postmenopause) (Kautzky-Willer, 2016; Isnaini dan Ratnasari, 2018). Rendahnya kadar estrogen dapat memengaruhi komposisi tubuh perempuan berupa peningkatan komponen lemak yang dapat meningkatkan resiko terjadinya resistensi insulin (Prasetyani \& Sodikin, 2017). Resistensi insulin menyebabkan sensitifitas dan ambilan glukosa darah terganggu dan akhirnya mengakibatkan gula terakumulasi tinggi dalam darah sehingga dapat meningkatkan resiko DM tipe 2.
Berdasarkan usia pasien DM tipe 2 mengalami peningkatan pada rentang 36-65 tahun dan mengalami penurunan jumlah pasien di usia $>65$ tahun. Hal ini terjadi karena pada saat usia 36-65 tahun peningkatan lemak tubuh terutama pada bagian adiposit visceral dapat mengurangi sensitifitas insulin. Sensitifitas insulin yang semakin menurun dapat menyebabkan resistensi insulin, yang pada akhirnya menyebabkan ketidakmampuan sel beta pankreas dalam mengkompensasi resistensi insulin sehingga dapat meningkatkan resiko DM tipe 2 (Suastika, Dwipayana, Semadi, dan Kuswardhani, 2012).

Tabel 1. Karakteristik pasien yang memenuhi kriteria inklusi ( $\mathrm{n}=112$ pasien)

\begin{tabular}{lcc}
\hline \multicolumn{1}{c}{ Variabel } & Jumlah & $\begin{array}{c}\text { Persentase } \\
(\mathbf{\%})\end{array}$ \\
\hline Jenis kelamin & 51 & \\
Laki-laki & 61 & 45,54 \\
Perempuan & & 54,46 \\
\hline Rentang usia (tahun) & 0 & \\
17 - 25 & 0 & 0 \\
26 - 35 & 10 & 0 \\
36 - 45 & 30 & 8,93 \\
46 - 55 & 47 & 26,77 \\
56 - 65 & 25 & 41,96 \\
$>$ 65 & & 22,32 \\
\hline Penyakit Penyerta*) & 28 & \\
Hipertensi & 9 & 30,44 \\
PJK/CAD & 6 & 9,79 \\
Hiperlipidemia & 5 & 6,52 \\
HHD & 5 & 5,44 \\
Gagal jantung kongestif & 4 & 5,44 \\
Cacat tetap Stroke & 4 & 4,35 \\
Stroke Infark & 2 & 4,35 \\
Anemia & 2 & 2,17 \\
Penyakit jantung iskemik & 2 & 2,17 \\
Diabetes neuropati & 25 & 2,17 \\
Penyakit lainnya & & 27,17 \\
\hline * Berdasarkan ICD-10 & &
\end{tabular}

Penurunan kejadian DM tipe 2 di usia geriatri disebabkan oleh sifat asimptomatik yang biasa terjadi pada pasien geriatri sehingga pasien sering tidak menyadari adanya penyakit ini dan menjadikan diagnosis terlambat bahkan terdiagnosis setelah timbul penyakit lain (komplikasi) (Kurniawan, 2010). Oleh sebab itu, American Diabetes Association (ADA) menganjurkan penapisan (screening) DM tipe 2 sebaiknya dilakukan terhadap orang dengan usia 45 tahun ke atas dengan interval 3 tahun sekali.

Berdasarkan penyakit penyerta pasien DM tipe 2 banyak mengalami penyakit hipertensi. Hubungan antara kejadian diabetes dengan hipertensi adalah terletak pada kejadian resistensi insulin dan hiperinsulinemia yang dapat menyebabkan terjadinya peningkatan tekanan darah (Putra, Wirawati, dan 
Mahartini, 2019). Hiperinsulinemia yang biasa terjadi pada pasien DM tipe 2 dapat memicu peningkatan retensi natrium oleh tubulus ginjal sehingga pada akhirnya menyebabkan keadaan hipertensi. Penyakit penyerta yang diderita oleh pasien DM tipe 2 di instalasi rawat jalan RSUD Provinsi NTB tahun 2018 selain hipertensi adalah penyakit jantung koroner, hiperlipidemia, heart hypertensive disease, gagal jantung kongestif, cacat tetap stroke, stroke infark, anemia, penyakit jantung iskemik, diabetes neuropati, hiperurisemia, atrial fibrilasi, STEMI (infark miokard), hemiplegia, dispnea, dispepsia, osteoarthritis, nyeri punggung bawah, gagal ginjal kronis, infeksi saluran kemih, retensi urin, asma, obstruksi saluran empedu dan hepatitis.

Berdasarkan profil penggunaan obat antidiabetes, obat yang paling banyak diresepkan adalah metformin yakni sebesar 33,85 \%. Profil penggunaan obat antidiabetes secara rinci dapat dilihat pada tabel 2. Metformin merupakan terapi lini pertama yang direkomendasikan karena terbukti efektif, aman, murah dan dapat menurunkan resiko kejadian kardiovaskular pada pasien DM tipe 2. Metformin juga memiliki banyak manfaat dalam terapi terkait kadar HbA1C, berat badan dan kematian yang disebabkan kejadian kardiovaskular (American Diabetes Association, 2019). Bukti bahwa metformin memiliki manfaat tersebut dijelaskan dalam beberapa hasil uji dan kumpulan data observasi (Zilov et al., 2019).

Tabel 2. Profil penggunaan obat antidiabetes

\begin{tabular}{|c|c|c|c|}
\hline Nama Obat & Jumlah & $\begin{array}{l}\text { Persentase } \\
(\%)\end{array}$ & $\begin{array}{l}\text { Persentase } \\
\text { Total (\%) }\end{array}$ \\
\hline \multicolumn{4}{|l|}{ Biguanid } \\
\hline Metformin & 66 & 33,85 & 33,85 \\
\hline \multicolumn{4}{|l|}{ Sulfonilurea } \\
\hline Gliklazid & 3 & 1,54 & \multirow{3}{*}{28,21} \\
\hline Gliquidone & 3 & 1,54 & \\
\hline Glimepirid & 49 & 25,13 & \\
\hline \multicolumn{4}{|l|}{ Tiazolidindion } \\
\hline Pioglitazone & 13 & 6,67 & 6,67 \\
\hline \multicolumn{4}{|c|}{ Penghambat alfa - glukosidase } \\
\hline Acarbose & 3 & 1,54 & 1,54 \\
\hline \multicolumn{4}{|l|}{ Insulin } \\
\hline Insulin lispro & 1 & 0,51 & \multirow{5}{*}{29,75} \\
\hline Insulin aspart & 26 & 13,33 & \\
\hline Insulin regular & 2 & 1,03 & \\
\hline Insulin glargine & 13 & 6,67 & \\
\hline Insulin detemir & 16 & 8,21 & \\
\hline $\begin{array}{l}\text { Jumlah obat } \\
\text { antidiabetes }\end{array}$ & 195 & 100 & 100 \\
\hline
\end{tabular}

Penggunaan sulfonilurea juga cukup banyak diresepkan. Mekanisme obat golongan sulfonilurea adalah dengan meningkatkan sekresi insulin (PB PERKENI, 2015). Sulfonilurea mampu mengurangi kadar glukosa darah sampai $20 \%$ dan kadar HbA1C 1$2 \%$, namun golongan ini rentan menyebabkan efek hipoglikemi pada pasien geriatri dan tidak dianjurkan pada pasien dengan berat badan lebih / beresiko karena dapat memberikan efek penambahan berat badan sampai $2 \mathrm{~kg}$ (Sola et al., 2015).

Tiazolidindion dan penghambat alfa-glukosidase juga diresepkan meskipun tidak sebanyak terapi metformin maupun sulfonilurea. Penelitian terkait penggunaan tiazolidindion pada pasien DM tipe 2 menunjukkan bahwa terapi dengan golongan ini dapat digunakan pada pasien dengan komplikasi beberapa penyakit seperti gangguan metabolisme, penyakit hati, ateroskerosis, inflamasi, infertilitas, bahkan kanker. Namun, pertimbangan terhadap efek "off-target / offlabel" yang dimiliki patut diwaspadai karena dapat memicu efek yang tidak diinginkan (efek samping obat), seperti edema, penambahan berat badan, bahkan gagal jantung (Rizos et al., 2009; Yau et al., 2013). Pada golongan penghambat alfa-glukosidase, efek kontrol glukosa darah yang dihasilkan lebih rendah dibandingkan dengan sulfonilurea, akan tetapi golongan ini tetap mampu menurunkan kadar insulin basal dan prandial sehingga masih dapat digunakan untuk terapi DM tipe 2 (Van De Laar et al., 2005).

Terapi insulin diberikan pada pasien dengan kadar $\mathrm{HbA} 1 \mathrm{C}>9.0 \%$ dan / atau pasien yang tidak mencapai target glukosa darah ketika diterapi dengan obat oral baik secara monoterapi maupun kombinasi. Adapun dasar terapi insulin adalah untuk mencapai kadar insulin fisiologis. Terapi insulin dapat berupa terapi insulin basal, insulin prandial atau keduanya. Terapi insulin basal adalah terapi yang ditujukan untuk glukosa darah puasa, sedangkan insulin prandial ditujukan untuk glukosa darah 2 jam post prandial (PB PERKENI, 2015).

\section{Kesimpulan}

Pada penelitian ini dapat disimpulkan profil penggunaan obat antidiabetes telah sesuai dengan rekomendasi pedoman (Konsenus Pengelolaan dan Pencegahan Diabetes Mellitus Tipe 2 di Indonesia 2015 oleh PB Perkeni dan Standard of Medical Care in Diabetes 2018-2019 oleh American Diabetes Assosiaciton). Penelitian lebih lanjut terkait telaah resep serta indikasi secara rinci perlu dilakukan untuk meningkatkan kerasionalan penggunaan obat, menurunkan morbiditas dan mortalitas serta menurunkan biaya pengobatan. 


\section{Daftar Pustaka}

Almasdy, D., Sari, D. P., Suhatri, S., Darwin, D., \& Kurniasih, N. (2015). Evaluasi Penggunaan Obat Antidiabetik Pada Pasien Diabetes Melitus Tipe-2 di Suatu Rumah Sakit Pemerintah Kota Padang Sumatera Barat. Jurnal Sains Farmasi \& Klinis, 2(1), 104. https://doi.org/10.29208/jsfk.2015.2.1.58

American Diabetes Association. (2018). Standards of Medical Care in Diabetes 2018. The Journal OfClinical and Applied Research and Education, 41, 2045-2047. https://doi.org/10.2337/dc18-su09

American Diabetes Association. (2019a). 9. Pharmacologic approaches to glycemic treatment: Standards of medical care in diabetes - 2019. Diabetes Care, 42(supp 1), S90-S102. https://doi.org/10.2337/dc19-S009

American Diabetes Association. (2019b). Standards of Medical Care In Diabetes - 2019. Diabetes Care, Supp 1.

Cho, N. H., Shaw, J. E., Karuranga, S., Huang, Y., da Rocha Fernandes, J. D., Ohlrogge, A. W., \& Malanda, B. (2018). IDF Diabetes Atlas: Global estimates of diabetes prevalence for 2017 and projections for 2045. Diabetes Research and Clinical Practice, 138, 271-281. https://doi.org/10.1016/j.diabres.2018.02.023

Dinas Kesehatan NTB. (2017). Profil Kesehatan Provinsi Nusa Tenggara Barat Tahun 2017. In Provinsi Nusa Tenggara Barat Tahun 2017. Dinas Kesehatan Provinsi Nusa Tenggara Barat.

Edwina, D., \& Manaf, A. (2015). Pola Komplikasi Kronis Penderita Diabetes Melitus Tipe 2 Rawat Inap di Bagian Penyakit Dalam RS. Dr. M. Djamil Padang. Jurnal Kesehatan Andalas, 4(1), 102-106. http://jurnal.fk.unand.ac.id/index.php/jka/artic le/view/207

International Diabetes Federation. (2013). IDF Diabetes Atlas Sixth Edition 2013. International Diabetes Federation.

International Diabetes Federation. (2017). IDF Diabetes Atlas Eighth Edition 2017. In IDF Diabetes Atlas, 8th edition. International Diabetes Federation. https://doi.org/http://dx.doi. org/10.1016/S0140-6736(16)31679-8.

Isnaini, N., \& Ratnasari, R. (2018). Faktor risiko mempengaruhi kejadian Diabetes mellitus tipe dua. Jurnal Kebidanan Dan Keperawatan Aisyiyah, 14(1), 59-68. https://doi.org/10.31101/jkk.550

Kautzky-Willer, A., Harreiter, J., \& Pacini, G. (2016). Sex and gender differences in risk, pathophysiology and complications of type 2 diabetes mellitus. In Endocrine Reviews (Vol. 37, Issue 3, pp. 278-316). Endocrine Society. https://doi.org/10.1210/er.2015-1137

Kurniawan, I. (2010, December). Diabetes Melitus Tipe 2 pada Usia Lanjut. Majalah Kedokteran Indonesia, 60(12), 576-584. https://doi.org/10.3928/00989134-19941101-20

Murad, M. A., Abdulmageed, S. S., Iftikhar, R., \& Sagga, B. K. (2014). Assessment of the common risk factors associated with type 2 diabetes mellitus in jeddah. International Journal of Endocrinology, 1-9. https://doi.org/10.1155/2014/616145

PB PERKENI. (2015). Konsensus Pengelolaan dan Pencegahan Diabetes Melitus Tipe 2 di Indonesia 2015. PB Perkeni.

Prasetyani, D., \& Sodikin. (2017). Analisis Faktor Yang Mempengaruhi Kejadian Diabetes Melitus (DM) Tipe 2. Jurnal Kesehatan Al Irsyad, 10(2), 1-9.

Psarakis, H. M. (2006). Clinical challenges in caring for patients with diabetes and cancer. Diabetes Spectrum, 19(3), 157-162. https://doi.org/10.2337/diaspect.19.3.157

Putra, I. D. G. I. P., Wirawati, I. A. P., \& Mahartini, N. N. (2019). Hubungan Kadar Gula Darah dengan Hipertensi pada Pasien Diabetes Mellitus Tipe 2 di RSUP Sanglah. Intisari Sains Medis, 10(3), 797800. https://doi.org/10.15562/ism.v10i3.482

Rizos, C. V., Elisaf, M. S., Mikhailidis, D. P., \& Liberopoulos, E. N. (2009). How safe is the use of thiazolidinediones in clinical practice? Expert Opinion on Drug Safety, 8(1), 15-32. https://doi.org/10.1517/14740330802597821

Sola, D., Rossi, L., Schianca, G. P. C., Maffioli, P., Bigliocca, M., Mella, R., Corlianò, F., Paolo Fra, G., Bartoli, E., \& Derosa, G. (2015). Sulfonylureas and their use in clinical practice. Archives of Medical Science, $\quad 11(4), \quad 840-848$. https://doi.org/10.5114/aoms.2015.53304

Suastika, K., Dwipayana, P., Semadi, M. S., \& 
Kuswardhani, R. A. T. (2012). Age is an Important Risk Factor for Type 2 Diabetes Mellitus and Cardiovascular Disease. Book Citation Index. https://doi.org/10.1016/j.colsurfa.2011.12.014

Van De Laar, F. A., Lucassen, P. L., Akkermans, R. P., Van De Lisdonk, E. H., Rutten, G. E., \& Van Weel, C. (2005). a-Glucosidase inhibitors for patients with type 2 diabetes: Results from a Cochrane systematic review and meta-analysis. In Diabetes Care (Vol. 28, Issue 1, pp. 154-163). American Diabetes Association. https://doi.org/10.2337/diacare.28.1.154

Yau, H., Rivera, K., Lomonaco, R., \& Cusi, K. (2013). The Future of Thiazolidinedione Therapy in the Management of Type 2 Diabetes Mellitus. Current Diabetes Reports, 13(3), 329-341. https://doi.org/10.1007/s11892-013-0378-8

Zilov, A. V., Abdelaziz, S. I., AlShammary, A., Al Zahrani, A., Amir, A., Assaad Khalil, S. H., Brand, K., Elkafrawy, N., Hassoun, A. A. K., Jahed, A., Jarrah, N., Mrabeti, S., \& Paruk, I. (2019). Mechanisms of action of metformin with special reference to cardiovascular protection. Diabetes/Metabolism Research and Reviews, 35(7), 112. https://doi.org/10.1002/dmrr.3173 